Terr. Atmos. Ocean. Sci., Vol. 17, No. 3, 547-561, September 2006

\title{
Resistivity Structures of the Chelungpu Fault in the Taichung Area, Taiwan
}

\author{
Ping-Hu Cheng ${ }^{1, *}$, Andrew Tien-Shun Lin ${ }^{1}$, Yueh-luan Ger ${ }^{1}$, and Kuan-Hung Chen ${ }^{1}$
}

(Manuscript received 4 November 2005, in final form 31 August 2006)

\begin{abstract}
We conducted magnetotelluric prospecting in the Taichung area to investigate subsurface resistivity structures of the Chelungpu fault and the resistivity of rock formations. The results indicate that the Chelungpu fault is a complex fault system consisting of two major fault zones, several fracture zones, and back thrust. The two major fault zones, the basal and the Chi-Chi fault zone are about $800 \mathrm{~m}$ apart on the ground and converge to a narrow band at a depth of $3000 \mathrm{~m}$. The fault zones are not smooth, composed of ramps and platforms with an average eastward dipping angle of $35^{\circ}-37^{\circ}$ within the depth of $3000 \mathrm{~m}$. In the shallower region, the basal fault zone has developed along the boundary of the Toukoshan Formation (resistivity: 200 - $400 \Omega-\mathrm{m}$ ) at the footwall and the Neogene formations on the hanging wall, where the Cholan Formation, the Chinshiu Shale, and the Kueichulai Formation have respective resistivity mainly in the ranges: $40-100,8-60$, and $50-150 \Omega-m$. While the Chi-Chi fault zone has developed along the weak layers of the Cholan Formation where resistivity is lower than the unsheared block.

At the TCDP site, the use of MT soundings, prior to TCDP drilling, predicted the position of the Chi-Chi fault zone to be at a depth between $1100 \mathrm{~m}$ and $1250 \mathrm{~m}$. Drilling subsequently confirmed this result, indicating MT sounding to be a reliable approach in revealing subsurface structures.
\end{abstract}

(Key words: Resistivity structures, Magnetotellurics, Chelungpu fault)

\section{INTRODUCTION}

The reactivation of the Chelungpu fault in Central Taiwan in 1999 resulted in the disastrous Chi-Chi earthquake. A 2-km deep drilling project (Taiwan Chelungpu Drilling Project,

\footnotetext{
${ }^{1}$ Institute of Geophysics, National Central University, Chung-Li, Taiwan, ROC

* Corresponding author address: Prof. Ping-Hu Cheng, Institute of Geophysics, National Central University, Chung-Li, Taiwan, ROC; E-mail: huh@geps.gep.ncu.edu.tw
} 
TCDP) was conducted from January 2004 to January 2005 to study the fault. The site is about $2 \mathrm{~km}$ east of the surface rupture of the Chi-Chi earthquake. Prior to drilling, many geophysical investigations were conducted to assist in the drilling project. Post drilling, the results of the drilling project provide useful data for examining the effectiveness of the geophysical techniques engaged in this initial investigation.

The Chelungpu fault is an eastward dipping thrust, characterized by the Pliocene Chinshui Shale on the hanging wall and Quaternary formations on the footwall (Pan 1967; Chang 1971). Some surface ruptures associated with the Chi-Chi earthquake are not consistent with the formerly suggested fault zone; these appeared on the Cholan Formation, a formation on the hanging wall to the east of Taichung.

Two boreholes were drilled in 2001 at Fengyuan (Taichung area) to the north and Nantou to the south of the Chelungpu fault for academic studies. The Nantou core showed that the Chelungpu fault zone was at the bottom of the Chinshui Shale with the Quaternary Toukoshan Formation on the footwall (Huang et al. 2002). This structure is consistent with a previously suggested model (Pan 1967; Chang 1971). The Fengyuan core showed a different result, the Chelungpu fault was at the bottom of the Chinshui Shale but with the Mio-Pliocene Kueichulin Formation at the footwall (Huang et al. 2002; Tanaka et al. 2002). A reflection seismic section presented by Wang et al. (2002) showed that the Chelungpu fault would have met the Kueichulin Formation under the TCDP site, but nothing about the Quaternary formations was found. Questions about the nature of the Chelungpu fault have since been raised; such as: Is there a boundary with the Pliocene or Miocene rocks on the hanging wall and with the Quaternary formations on the footwall in the Taichung area? If there is, where is it located? And how is it related to the Chelungpu fault? Clues to the answers to these questions may lay in structures thousands of meters below the surface. The intention of this study is to investigate resistivity spectra and resistivity structures of these formations to find answers to these questions; and we believe magnetotellurics is a suitable method for such an investigation.

\section{GEOLOGICAL SETTING}

The study area is located in the eastern part of Taichung City; an area covered with Quaternary and Neogene formations. The boundaries between formations trend generally in a N-S direction (Fig. 1). From west to east, they are the Holocene alluvium, the late Pleistocene lateritic terrace deposits, the Pliocene Cholan Formation, and the Pleistocene Toukoshan Formation (Ho and Chen 2000).

The alluvium is distributed on the plain in the western part of the study area and is underlain by the Toukoshan Formation. The boundary between the alluvium and the lateritic terrace deposits has previously been suggested as the fault line of the Chelungpu fault and is the southern extension of the Sanyi fault (Meng 1963; Pan 1967; Chang 1971). The boundary between the terrace of lateritic deposits and the Cholan Formation may be a fault plane of the Chelungpu fault system. The surface rupture of the Chi-Chi earthquake is near this boundary. In the eastern part of the study area, the Cholan Formation is overlain conformably by the Toukoshan Formation. Below the surface, the Cholan Formation is underlain by the Pliocene Chinshui Shale and the Mio-Pliocene Kueichulin Formation successively. 


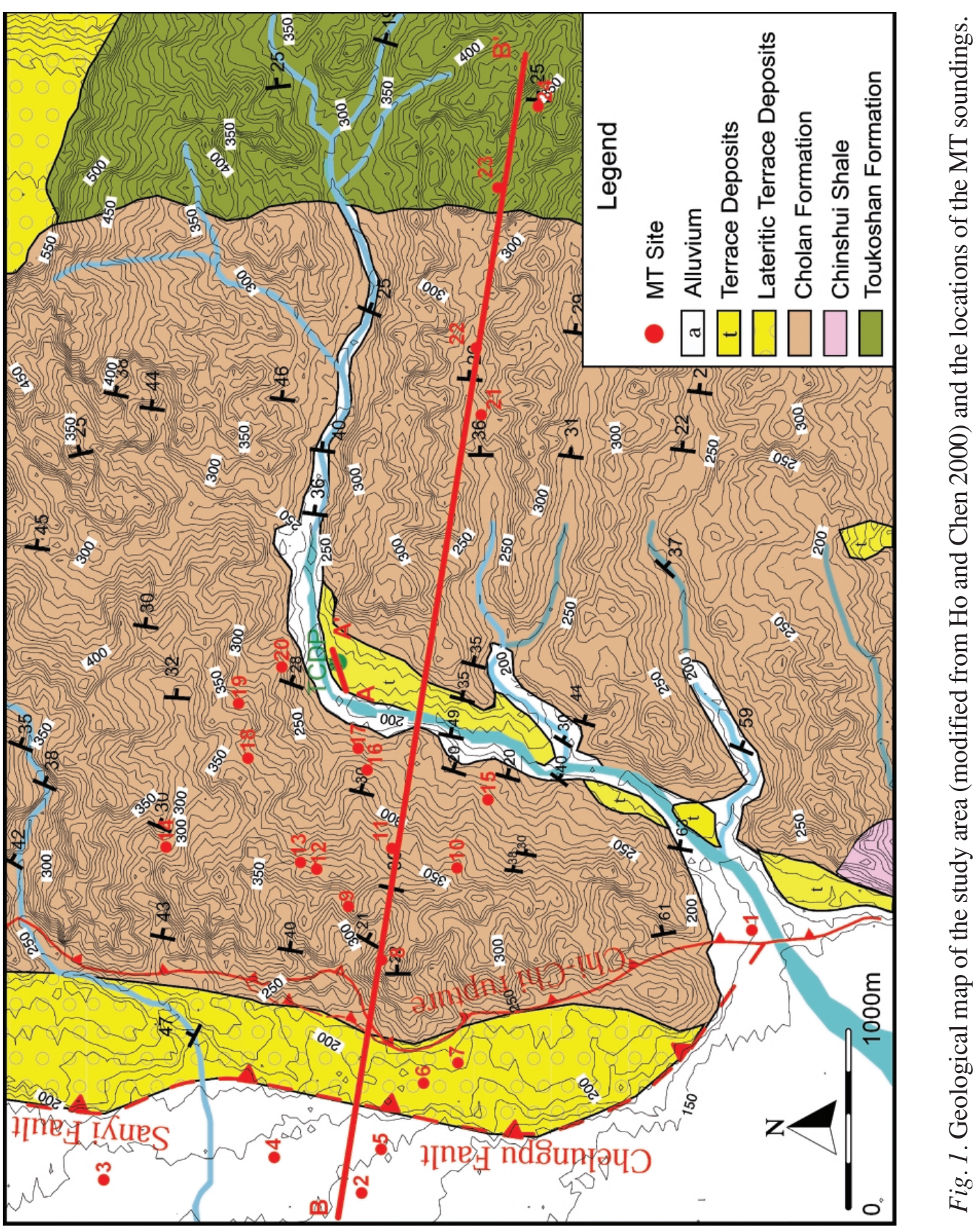




\section{METHOD AND EQUIPMENT}

The magnetotelluric method (MT) is used to investigate resistivity structures of the strata in this study. In an MT sounding, a pair of electric field and magnetic field receivers are set perpendicularly to each other on the ground to acquire data. Based on the electromagnetic (EM) theory, the electric and magnetic fields (EM fields) measured on the ground are the response of the EM induction of the earth when the EM waves are penetrating into and traveling through the ground. The original EM fields in nature were generated by lightnings and EM interactions in the atmosphere and the magnetosphere (Vozoff 1991).

The amplitude of the EM fields is reduced exponentially in the ground. A commonly used criterion for this decay is the skin depth $\delta$, in which the amplitude is reduced by $1 \mathrm{e}^{-1}$, i.e., by about 0.37 . Skin depth is a function of the EM properties of the medium and the frequency of the wave. It can be expressed as:

$$
\delta=\sqrt{\frac{\rho}{\pi f \mu}},
$$

where $\rho$ and $\mu$ are the electric resistivity and the magnetic permeability of the medium, respectively, and $f$ is the frequency of the EM wave. It shows that a wave of lower frequency will penetrate deeper at a given site.

For a plane EM wave in a 1-D nonferromagnetic earth, the apparent resistivity $\rho_{a}$ can be expressed by:

$$
\rho_{a}=\frac{\mu_{0}}{2 \pi f}\left|\frac{E_{x}}{B_{y}}\right|^{2},
$$

where $\mu_{0}$ is the magnetic permeability of the free-space, and $E_{x}$ and $B_{y}$ are a pair of electric and magnetic fields in orthogonal directions. Usually, the apparent resistivity $\rho_{a}$ varies with frequency. Since the wave of lower frequency has a greater skin depth, therefore, the apparent resistivity of the higher frequencies reflects the property of the shallower strata and that of the lower frequencies response to the deeper part. The apparent resistivity does not show the true resistivity of a stratum, but an equivalent to that frequency. Using the apparent resistivities and the phases in various frequencies, the true resistivities of strata are obtained by proper interpretation (Vozoff 1991).

In this study, Stratagem was used in MT soundings, an instrument made by the Geometrics, Inc., USA that can acquire data in two frequency bands. The higher band ranges from 100 to $11.7 \mathrm{~Hz}$ and the lower band ranges from 1000 to $0.1 \mathrm{~Hz}$. The data in the two bands are collected separately. Usually, two-EM-Field couplets $E_{x}$ and $B_{y}$, and $E_{y}$ and $B_{x}$, are measured simultaneously (vector measurement) in a layout, where $\mathrm{x}$ and y denote the two orthogonal directions; thereby allowing for two directional apparent resistivities to be obtained during 
measurement. In each site, two vector measurements with a $45^{\circ}$ rotation about the origin were conducted, giving four phase-accompanied directional apparent resistivities.

The sounding data at the separate sites were interpreted by 1-D analysis and those along a profile were interpreted by 2-D analysis (Bostick 1977; Jones et al. 1989).

The sounding data and the 1-D analysis results are displayed in terms of apparent resistivity, phase and coherency vs. frequency and true resistivity vs. depth. Figure 2 shows the sounding results for site DKL-9. In Fig. 2, the apparent resistivity and phase are data calculated from the EM fields. The true resistivities exhibited in the lower block are the 1-D analyzed results. The coherency indicates the data quality. Analyzed results are acceptable for data of high coherency ( $>0.9$ ), as for that of low coherency are considered unreliable. Consequently, interpreted results with coherency lower than 0.5 are discarded, such as results from that part of the frequency less than $1 \mathrm{~Hz}$ for the sounding at DKL-9. The interpretative results can be stratified based on resistivity ranges with boundaries at the resistivity gradient maxima. The electrostratigraphy of the earth at site DKL-9 is shown in Fig. 2b. It shows that the earth is anisotropic.

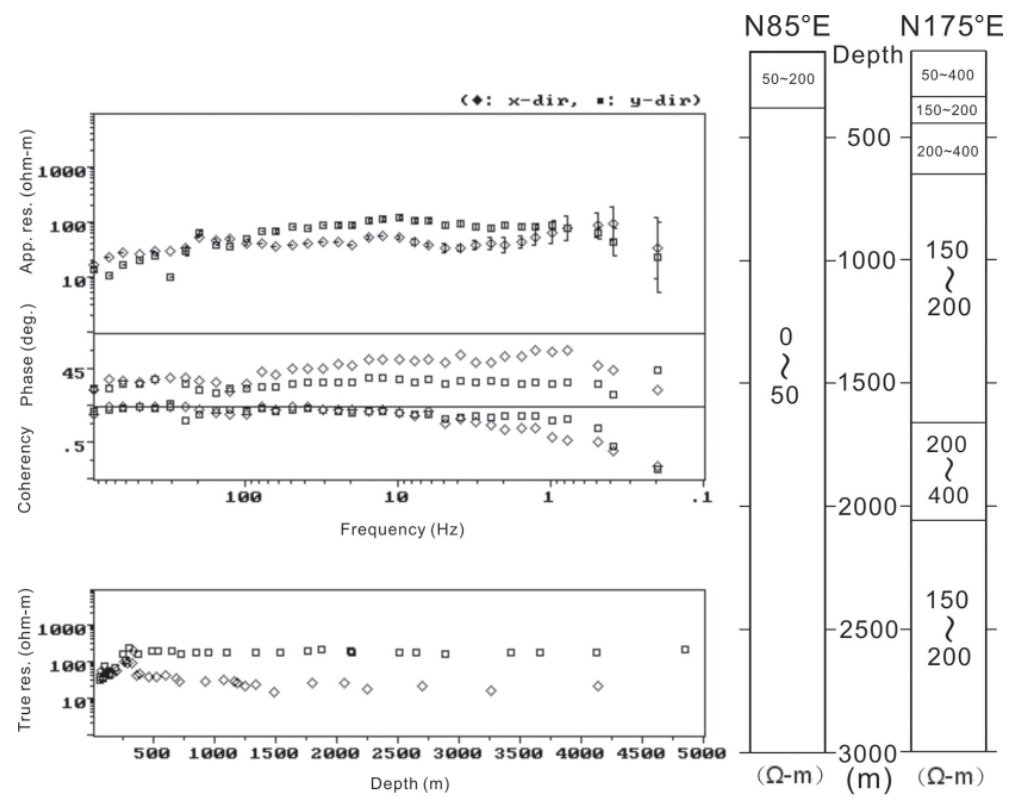

(a)

(b)

Fig. 2. (a) The MT sounding results of DKL-9. It is located at the TCDP site and is measured in both the directions of $\mathrm{N} 85^{\circ} \mathrm{E}$ (diamond) and $\mathrm{N} 175^{\circ} \mathrm{E}$ (square). The marks, diamond and square, denote the directions of the measured electric field components. The coherency indicates the data quality. The true resistivity exhibited on the lower block is obtained from 1-D analysis. The directional apparent resistivities diverge outward in a frequency band of $100-1 \mathrm{~Hz}$; (b) The resistivity columns of DKL-9 drawn from the 1-D analyzed results. 


\section{RESULTS}

In order to get a better interpretative model for the earth at the TCDP site, especially the depth of the Chelungpu fault and the formations to be met whilst boring, a high data density survey, consisting of forty-nine MT soundings along a profile of length $200 \mathrm{~m}$ across the TCDP site, was conducted. The location of the profile is denoted by AA' in Fig. 1. The profiling data were interpreted by 2-D analysis since the layers on the ground dip eastward monotonously like a 2-D structure. In addition to the profiling survey, twenty-four MT soundings at separate sites (denoted by MT1 - 24 in Fig. 1) were conducted to investigate the features of the Chelungpu fault and rock units in the study area.

\subsection{Profile AA'}

Profile AA' is situated at the central part of the study area (Fig. 1). The length of the profile $\mathrm{AA}^{\prime}$ is $200 \mathrm{~m}$, trending in a $\mathrm{N}^{\circ} 5^{\circ} \mathrm{E}$ direction, and the borehole of the TCDP is $160 \mathrm{~m}$ from the western end of the profile. The profile consists of twenty-seven high frequency soundings (DKH-1 to 27) and twenty-two low frequency soundings (DKL-1 to 22). The sounding sites were spread along the profile with a station interval of $15 \mathrm{~m}$ for high frequency measurements and $20 \mathrm{~m}$ for low frequency measurements. The high frequency soundings DKH-1 to 14 and the low frequency soundings DKL- 1 to 11 were measured in both $\mathrm{N} 85^{\circ} \mathrm{E}$ and $\mathrm{N} 175^{\circ} \mathrm{E}$ directions, while the high frequency soundings DKH-15 to 27 and the low frequency soundings DKL-12 to 22 were measured in both $\mathrm{N} 40^{\circ} \mathrm{E}$ and $\mathrm{N} 130^{\circ} \mathrm{E}$ directions. The sounding sites DKH-11, DKH-24, DKL-9, and DKL-19 were located at the site of the TCDP.

All the high frequency soundings have a similar pattern of apparent resistivity curves. A representative curve of DKH-13 is shown in Fig. 3. The apparent resistivity is about $10 \Omega-\mathrm{m}$ at $10000 \mathrm{~Hz}$ and increases moderately as frequency decreases and has a slight depression around $100 \mathrm{~Hz}$. The great fluctuation of apparent resistivity in frequencies above $10000 \mathrm{~Hz}$, indicated by random phase and low coherency, was caused by noise.

The results of the low frequency soundings show that apparent resistivity curves corresponding to the same direction are similar in shape. The soundings at DKL-9 and DKL-19 are the representatives (Figs. 2, 4). It seems there is no obvious difference between directional apparent resistivities in frequency higher than $100 \mathrm{~Hz}$. The resistivities gradually increase from 20 to $40 \Omega-\mathrm{m}$ as the frequency decreases from 1000 to $100 \mathrm{~Hz}$ (Figs. 2, 4). The directional apparent resistivities in the directions $\mathrm{N} 85^{\circ} \mathrm{E}$ and $\mathrm{N} 175^{\circ} \mathrm{E}$ diverge outward as the frequency decreases from 100 to $2 \mathrm{~Hz}$ (Fig. 2) implying that the strata are anisotropic in the deeper zones. The directional apparent resistivities in the direction $\mathrm{N} 40^{\circ} \mathrm{E}$ are just slightly higher than that of the $\mathrm{N} 130^{\circ} \mathrm{E}$ direction (Fig. 4); the data are less reliable due to low coherency in frequency less than $2 \mathrm{~Hz}$.

The MT data measured along Profile AA' were analyzed by the 2-D inversion method. The interpreted results of the high frequency soundings accompanied with a portion of the E-log at the TCDP borehole are shown in Fig. 5. It shows that the resistivities interpreted from the MT data are higher than that in the E-log. This phenomenon could be explained by two reasons: (1) the mud in the borehole reduced resistivity as mud has a resistivity of about $4 \Omega-\mathrm{m}$; 


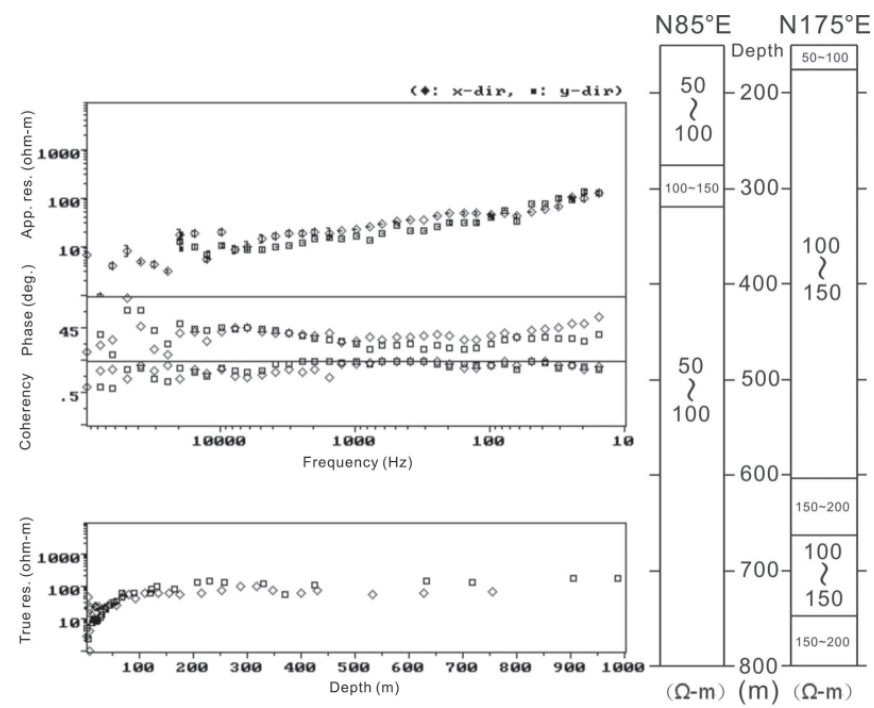

(a)

(b)

Fig. 3. (a) The sounding results of DKH-13. It is located $30 \mathrm{~m}$ to the east of the site of the TCDP and is measured in both the directions of $\mathrm{N}^{\circ} \mathrm{E}$ (diamond) and $\mathrm{N} 175^{\circ} \mathrm{E}$ (square); (b) The resistivity columns of DKL-13 showing anisotropy of the earth, which are drawn from the 1-D analyzed results.

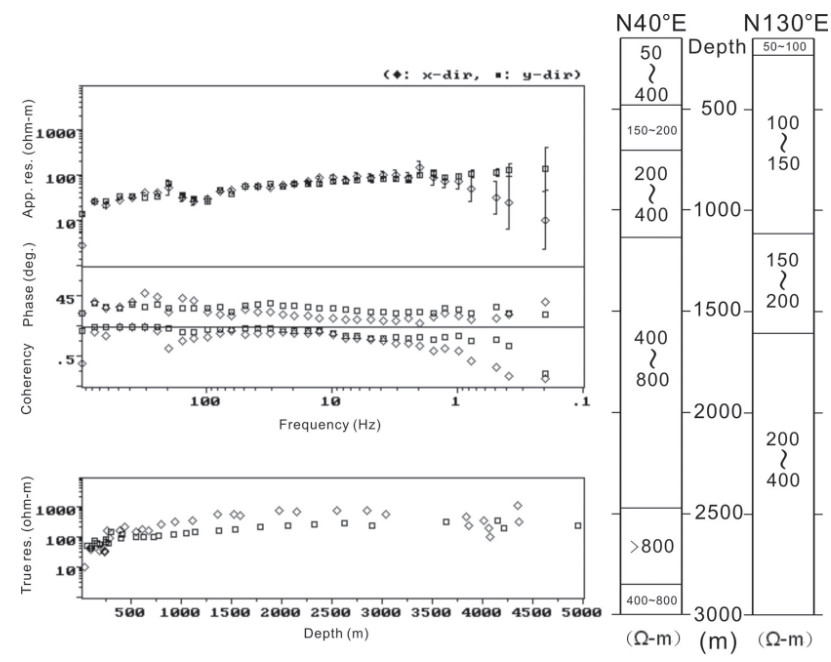

(a)

(b)

Fig. 4. (a) The sounding results of DKL-19. It is located at the TCDP site and is measured in both the directions of $\mathrm{N} 40^{\circ} \mathrm{E}$ (diamond) and $\mathrm{N} 130^{\circ} \mathrm{E}$ (square). The apparent resistivities in the $\mathrm{N} 40^{\circ} \mathrm{E}$ direction are slightly higher than that in the $\mathrm{N} 130^{\circ} \mathrm{E}$ direction; (b) The resistivity columns of DKL-19 drawn from the 1-D analyzed results. 


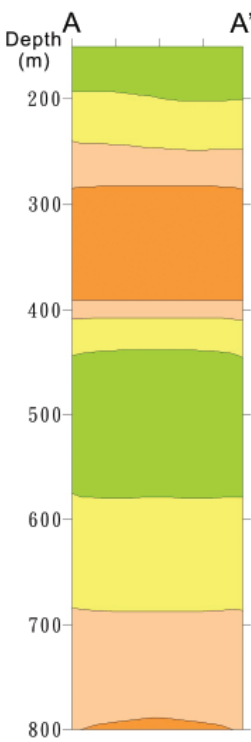

(a)

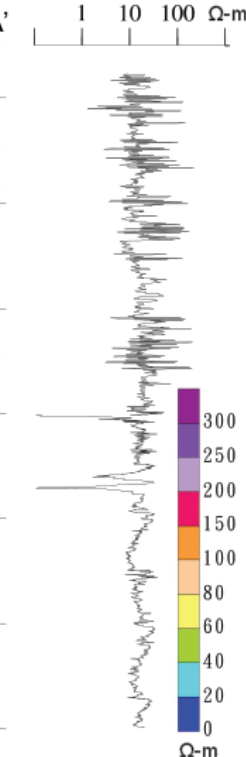

(b)

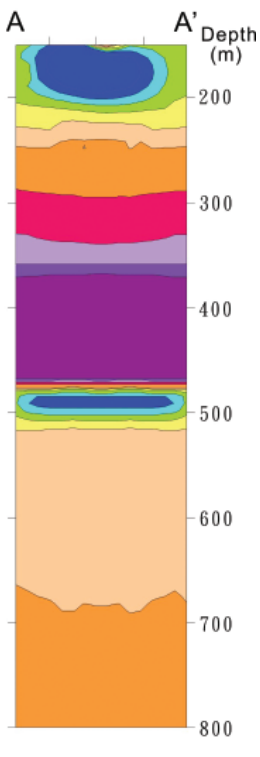

(c)

Fig. 5. Resistivity structures of Profile AA' drawn from the 2-D analyzed results of the high frequency MT soundings and a portion of the E-log in the borehole of the TCDP. (a) Resistivity in the $\mathrm{N} 85^{\circ} \mathrm{E}$ direction; (b) Resistivity in the E-log; (c) Resistivity in the $\mathrm{N} 40^{\circ} \mathrm{E}$ direction.

i.e., much lower than the strata, (2) the thicknesses of respondents were different; the MT sounding data are the responses of thick layers (several tens meters or more) while that of the E-log are the responses of thin layers (only a few meters). The resistivity structures derived from the data measured in the directions $\mathrm{N} 40^{\circ} \mathrm{E}$ and $\mathrm{N} 85^{\circ} \mathrm{E}$ are different (Figs. 5a, c), which means that the strata are anisotropic in electric resistivity. Although the strata are electrically anisotropic, the resistivity layer sequences are still similar, having a sequence of low-highlow-high in resistivity from top to bottom. Figure 5a shows that the top layer (50 - $200 \mathrm{~m}$ deep) has a relatively low resistivity $(15-60 \Omega-\mathrm{m})$, and the second layer has a relatively high resistivity $(60-150 \Omega-\mathrm{m})$ between the depths of $200-450 \mathrm{~m}$. The third layer has relatively low resistivity ( $40-60 \Omega-\mathrm{m}$ ) between the depths of $450-580 \mathrm{~m}$, and the bottom layer has a relatively high resistivity $(60-110 \Omega-\mathrm{m})$ between the depths of $580-800 \mathrm{~m}$. The similar resistivity layer sequence also appears in Fig. $5 c$, but the second layer is more resistive and thicker, and the third layer is more conductive and thinner than the corresponding layers shown in Fig. 5a. Figure 5b shows the resistivity of the strata measured in the E-log. Here the amplitude indicates the resistivity of the strata while the spacing of fluctuation indicates the thickness of the strata. The section corresponding to the top layer ( $<200 \mathrm{~m}$ deep) exhibits a small fluctuation in resistivity of $7-14 \Omega-\mathrm{m}$ mainly. The section corresponding to the second layer (200 - $460 \mathrm{~m}$ deep), however, exhibits a great and rapid fluctuation in resistivity of $10-80 \Omega-\mathrm{m}$ mainly; this is interpreted as being a formation of shale and sandstone in alternation as shale has a 
low resistivity of about $10-30 \Omega-\mathrm{m}$ while sandstone has a resistivity of about $60-150 \Omega-\mathrm{m}$. The section corresponding to the third layer ( $460-580 \mathrm{~m}$ deep) has a common resistivity range of $10-20 \Omega-\mathrm{m}$ and three extra low resistivity zones of less than $2 \Omega-\mathrm{m}$ at depths of 500 , 560 , and $580 \mathrm{~m}$. The section between $580-800 \mathrm{~m}$ has a small fluctuation in resistivity of 10 - $30 \Omega-$ m mainly. In general, fracture zones have a lower resistivity than the norm. Interpreting the results of the MT soundings and the E-log, the layer between $460-580 \mathrm{~m}$ has a low resistivity of $10-60 \Omega-\mathrm{m}$ and yet contains extra low resistivity zones. This indicates that the layer is a fine-grained formation with fracture zones.

The resistivity structures of Profile AA' derived from the 2-D interpreted results of the low frequency MT soundings and the E-log in the borehole of TCDP are shown in Fig. 6. Figure 6a shows the resistivity structures of profile AA' for resistivity in the $\mathrm{N} 85^{\circ} \mathrm{E}$ direction. The structures of this profile contain two major low resistivity zones (less than $50 \Omega-\mathrm{m}$ ); one exists between the depths of $470-520 \mathrm{~m}$ and the other between $650-1250 \mathrm{~m}$. The shallower zone was also found in the sections of the high frequency soundings. The deeper one is inferred to be a formation consisting of a large portion of mudstone and shale as they are characterized by such low resistivity. The base of this deeper low resistivity zone exhibited extra low resistivity and was consequently considered the position of the Chelungpu fault (Cheng et al. 2004). These inferences were confirmed by the TCDP, which showed that the Chi-Chi rupture

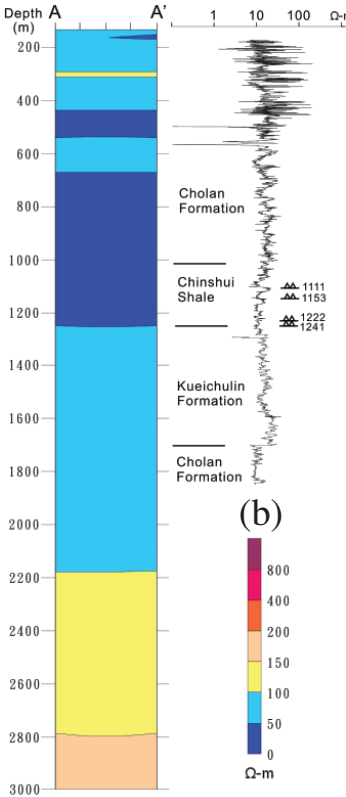

(a)

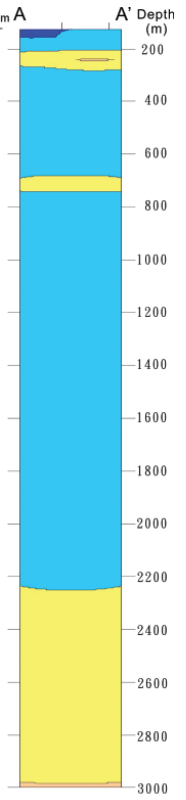

(c)

Fig. 6. Resistivity structures of Profile AA' drawn from the 2-D analyzed results of the low frequency MT soundings and the E-log in the borehole of the TCDP. (a) Resistivity in the $\mathrm{N} 85^{\circ} \mathrm{E}$ direction. (b) Resistivity in the E-log; (c) Resistivity in the $\mathrm{N} 40^{\circ} \mathrm{E}$ direction. 
occurred at depths of 1111, 1153, 1222, and $1241 \mathrm{~m}$ (Fig. 6b). No extra low resistivity zone corresponding to the Chi-Chi rupture was found in the $\mathrm{N} 40^{\circ} \mathrm{E}$ direction (Fig. 6c). Conversely, a relative high resistivity zone (100-150 $\Omega-\mathrm{m}$ ) exists between $690-730 \mathrm{~m}$, which correlates to a relative high resistivity layer that appears in the E-log (Fig. 6b). The differences between the results derived from the data measured in the $\mathrm{N} 85^{\circ} \mathrm{E}$ and $\mathrm{N} 40^{\circ} \mathrm{E}$ directions are explained as due to the anisotropy of the earth. The strikes of the Chelungpu fault and rock formations are in approximately the same direction; i.e., a N-S direction. Hence the MT sounding in the $\mathrm{N} 85^{\circ} \mathrm{E}$ direction may be considered a measurement of TM mode (transverse magnetic to vertical). It has a better response to low resistivity zones indicative of fracture zones, fault zones, and fine-grained strata.

\subsection{Soundings at Separate Sites}

Twenty-four MT soundings were conducted at separate sites in the study area. Their locations are shown in Fig. 1. About a half of the measured data were severely disturbed by noise, hence the related interpretative results are unreliable. The other half of the data were less disturbed with reasonable results for interpretation being obtained. The sounding MT1 is located at the southern part of the study area, which is $160 \mathrm{~m}$ away from the surface rupture of the ChiChi earthquake, and a borehole of $300 \mathrm{~m}$ deep drilled by the Central Geological Survey, Taiwan in 2002. The sounding results and the lithological column are shown in Fig. 7, in which the shale can be correlated to the top layer of $10-80 \Omega-\mathrm{m}$ in the resistivity column, and the gravel can be correlated to the section of resistivity $80-200 \Omega-\mathrm{m}$ below a depth of $130 \mathrm{~m}$. The shale layer could be the Chinshui Formation. The gravel layer is the Toukoshan Formation, which has a distinctively higher resistivity than its underlying Cholan Formation. At sounding site MT1, the MT sounding results (Fig. 7a) have the Toukoshan Formation as being thicker than $900 \mathrm{~m}$. The sounding sites MT2 - 7 are located on the western alluvial plain and the terrace of lateritic deposits in the study area (Fig. 1). The apparent resistivity patterns of MT2 to MT7 are similar in frequency less than $100 \mathrm{~Hz}$, MT6 is representative of the group and is shown in Fig. 8. The sounding result indicates that the section between $50-250 \mathrm{~m}$ deep has a resistivity of $10-80 \Omega-\mathrm{m}$ and that at $250-3000 \mathrm{~m}$ deep has a resistivity of $150-4000$ $\Omega-\mathrm{m}$ (Fig. 8). The low resistivity layer $(10-80 \Omega-\mathrm{m})$ in the shallower zone is inferred to be Neogene formations and the high resistivity layer $(150-4000 \Omega-\mathrm{m})$ below this is inferred to be Quaternary formations, which implies a fault exists. The sounding sites MT8 - 24 are situated on the east side of the surface rupture of the Chi-Chi earthquake. All the sounding curves have a depression around $100-10 \mathrm{~Hz}$, indicating a low resistivity zone at depth. Sounding MT9 is representative of the group and is shown in Fig. 9. The depression in the curve becomes more apparent at sites closer to the surface rupture of the Chi-Chi earthquake, implying the existence of a fault under the sites that deepens eastwardly.

\subsection{Profile BB'}

In order to describe the subsurface structures of the Chelungpu fault and to find the resistivity of the rock units, the resistivity structure across the study area of a west-east profile (BB' 

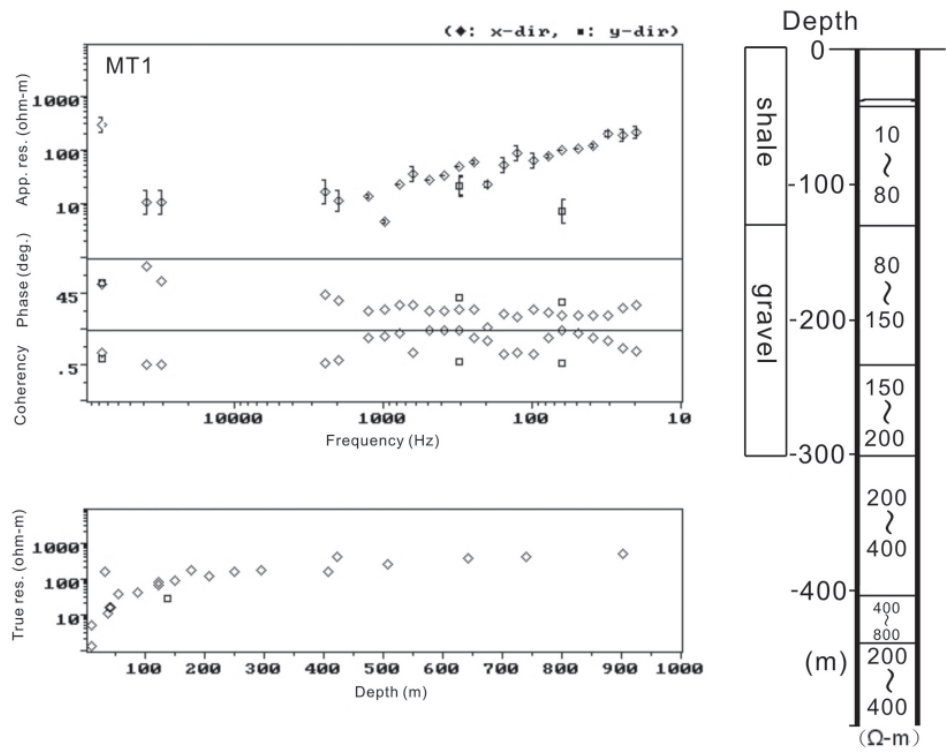

(a)

(b)

Fig. 7. (a) The sounding results of MT1; (b) Lithological column of the borehole at the site of MT1 (adapted from the Central Geological Survey, Taiwan); (c) Resistivity column drawn from the results of MT1. The shale has a resistivity of $10-80 \Omega-\mathrm{m}$ and the gravel beds have a resistivity of $80-200 \Omega-\mathrm{m}$.

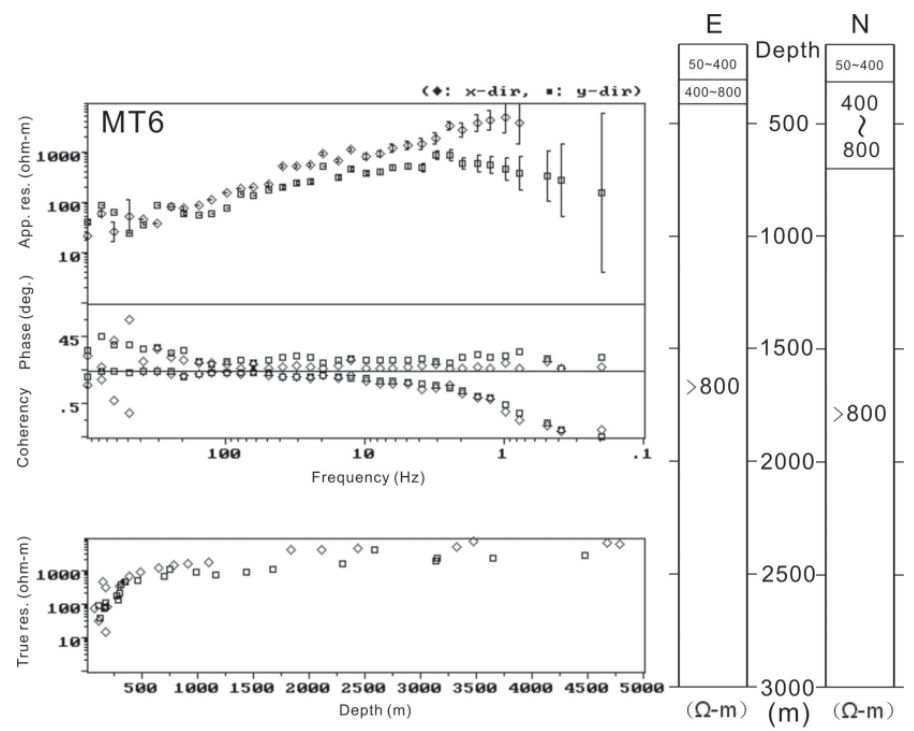

(a)

(b)

Fig. 8. The sounding results of MT6. 
in Fig. 1) is constructed and shown in Fig. 10. It contains the results of eleven MT soundings of sites near the line BB' and the results of Profile AA'.

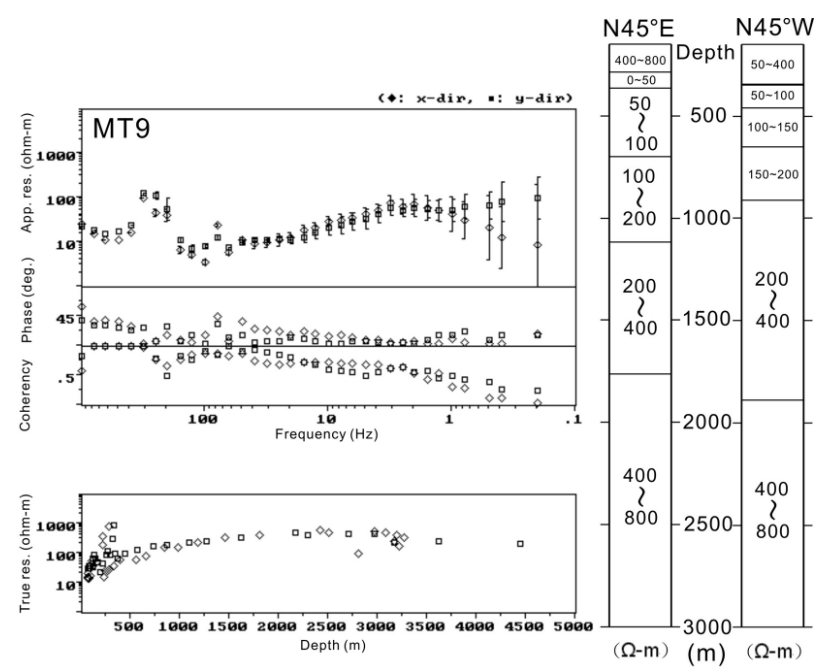

(a)

(b)

Fig. 9. The sounding results of MT9.

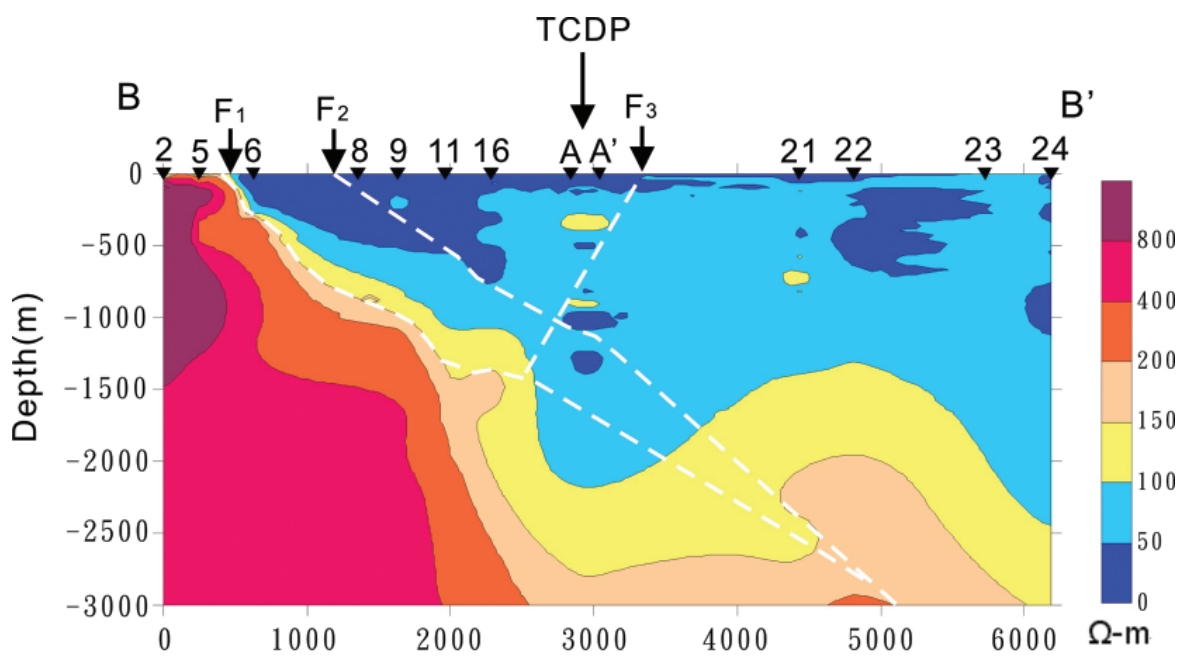

Fig. 10. Resistivity structures of Profile BB'. $\mathrm{F}_{1}$ is the basal fault plane; $\mathrm{F}_{2}$ is the Chi-Chi fault zone; and $\mathrm{F}_{3}$ is the back thrust inferred from the MT investigation. AA' denotes the location of the profile including the TCDP site. 
Usually, a fault has one of the following resistivity characteristics:

(1) A resistivity discontinuity or a great resistivity gradient due to different rocks or textures between both sides of a fault; (2) A lower resistivity zone due to fault gouge and water in the fracture zone as it is below the water table. It may exist in a rock formation or between two rock formations; (3) A higher resistivity zone due to more interstices and less water in the fracture zone as it is above the water table. It also may exist in a rock formation or between two rock formations. Figure 10 shows a resistivity discontinuity F1 between the sites of MT5 and MT6. The formation on the west side has the high resistivity (higher than $200 \Omega-\mathrm{m}$ ) of the Quaternary formations, which are interpreted to be the Toukoshan Formation and a thin layer of gravel and sandy soil. That on the east side has the low resistivity (less than $50 \Omega-\mathrm{m}$ ) of the Pliocene formations except for the lateritic terrace deposits. The resistivity discontinuity F1 is inferred to be the basal fault plane of the Chelungpu fault, since the fault is characterized by the westward thrusting of the Pliocene formations overlying the Quaternary formations near the ground surface. This basal fault plane can be depicted along the boundary between the high resistivity strata to the west and low resistivity layers to the east. It dips eastwardly and cuts through the low resistivity layer at a depth of $1707 \mathrm{~m}$ under the site of the TCDP (controlled by the drilling results), where the Kueichulin Formation overlays the Cholan Formation. The basal fault plane has an average east dipping angle of about $35^{\circ}$ as shown in Fig. 10.

The surface rupture associated with the Chi-Chi earthquake is situated between the sites of MT6 and MT8 (denoted by F2 in Fig. 10). An east dipping low resistivity zone can be depicted from the surface rupture to the fault zone at a depth of $1100-1250 \mathrm{~m}$ under Profile AA'. This low resistivity zone (denoted by a broken line in Fig. 10) is inferred to be the subsurface rupture associated with the Chi-Chi earthquake. It can be extended eastward and connected with an anticlinal drag, indicative the eastward extension of the fault zone.

The basal fault plane and the Chi-Chi rupture are about $800 \mathrm{~m}$ apart on the ground surface. They may converge together at a depth of $3000 \mathrm{~m}$ under the sites MT22 - 33. The low resistivity zone between 460 - $580 \mathrm{~m}$ under profile AA' is inferred to be the fault zone associated with back thrust due to a ramp under the site of MT16. The back thrust may appear to the east of profile AA', denoted by F3 in Fig. 10.

\section{DISCUSSIONS AND CONCLUSIONS}

1. In general, the sounding results in various directions are different, indicating the ground is anisotropic. This phenomenon can be caused by dipping beds or/and by directional fractures.

2. In the study area, the MT signals are severely disturbed in some directions, by noise from power lines, artificial construction containing iron, and unknown sources.

3. The Chi-Chi fault zone under the site of the TCDP was inferred to be at a depth of 1100 - $1250 \mathrm{~m}$ by the MT investigation prior to the TCDP. This result was confirmed by the results of the TCDP.

4. In the study area, the Toukoshan Formation has a resistivity of $800-4000 \Omega-m$ in the upper part (50-1500 m deep), and $200-800 \Omega-\mathrm{m}$ in the lower part. The Cholan 
Formation and the Chinshui Shale have a dominant resistivity of $40-100$ and $8-60 \Omega-\mathrm{m}$, respectively. The Kueichulin Formation has a resistivity of $50-100 \Omega-\mathrm{m}$ in the upper part and $100-150 \Omega-\mathrm{m}$ in the lower part.

5. Fault zones have a lower resistivity than normal. A low resistivity zone corresponding to a fault zone was found in the direction of TM mode but not in all directions by MT soundings.

6. The Chelungpu fault is a complex fault system of width greater than $800 \mathrm{~m}$ near the ground surface. It consists of two main fault zones, the basal and the Chi-Chi fault zones, minor fractures and back thrust. The basal fault zone has an average east-dipping angle of about $35^{\circ}$. The Chi-Chi fault zone has an average east-dipping angle of about $37^{\circ}$ and does not dip smoothly. The two fault zones may converge to within a narrow band at a depth of $3000 \mathrm{~m}$.

7. A buried anticlinal drag is found at $1500 \mathrm{~m}$ under the sites MT21 - 23 about $4 \mathrm{~km}$ east of the Chi-Chi rupture, on the hanging wall of the Chelungpu fault. It probably relates to the development of the fault.

Acknowledgements The authors are grateful to the diligent field crew of the Geoelectric Group at the Institute of Geophysics, National Central University. This study is supported by the National Science Council of Taiwan under the grant (NSC92-2116-M-008-004).

\section{REFERENCES}

Bostick, F. X., Jr., 1977: A simple almost exact method of MT analysis; Abstract in workshop on electrical method in geothermal exploration, Snowbird, Utah, USA.

Chang, S. L., 1971: Subsurface geologic study of the Taichung basin, Taiwan. Petrol. Geol. Taiwan, 9, 123-144.

Cheng, P. H., K. H. Chen, and Y. I. Ger, 2004: A geoelectric study of the formations in the Taichung-Tantz area. Abstract of 2004 conferrence in Geophysics, Taiwan. (in Chinese)

Ho, H. C., and M. M. Chen, 2000: Explanatory text of the geologic map of Taiwan, sheet Taichung. Central Geological Survey, Taiwan, 65 pp.

Huang, S. T., J. C. Wu, J. H. Hung, and H. Tanaka, 2002: Studies of sedimentary facies, stratigraphy, and deformation structures of the Chelungpu fault zone on cores from drilled wells in Fengyuan and Nantou, central Taiwan. Terr. Atmos. Ocean. Sci., 13, 253-278.

Jones, A. G., A. D. Chave., G. Egbert., D. Auld., and K. Bahr., 1989: A comparison of the techniques for magnetotelluric response function estimation. J. Geophys. Res., 94, 1420114213.

Meng, C. Y., 1963: San-I overthrust, Petrol. Geol. Taiwan, 2, 1-20.

Pan, Y. S., 1967: Interpretation and seismic coordination of the Bouguer gravity anomalies over west-central Taiwan. Petrol. Geol. Taiwan, 5, 99-115.

Tanaka, H., C. Y. Wang, W. M. Chen, A. Sakaguchi, K. Ujiie, H. Ito, and M. Ando, 2002: Initial science report of shallow drilling penetrating into the Chelungpu fault zone, 
Taiwan. Terr. Atmos. Ocean. Sci., 13, 227-251.

Vozoff, K., 1991: The magnetotelluric method. In: Nabighian (Ed.), Electromagnetic methods in applied geophysics, v.2, application, part B, Soc. Expl. Geophys., Tulsa, 641711.

Wang, C. Y., C. L. Li, F. C. Su, M. T. Leu, M. S. Wu, S. H. Lai, and C. C. Chern, 2002: Structural mapping of the 1999Chi-Chi earthquake fault, Taiwan by seismic reflection methods. Terr. Atmos. Ocean. Sci., 13, 211-226.

Cheng, P. H., A. T. S. Lin, Y. I. Ger, and K. H. Chen, 2006: Resistivity structures of the Chelungpu fault in the Taichung area, Taiwan. Terr. Atmos. Ocean. Sci., 17, 547-561. 